\title{
Pharmacokinetics and pharmacodynamic effect of crenezumab on plasma and cerebrospinal fluid beta-amyloid in patients with mild-to-moderate Alzheimer's disease
}

Kenta Yoshida ${ }^{1}$, Anita Moein ${ }^{1}$, Tobias Bittner ${ }^{2}$, Susanne Ostrowitzki ${ }^{1}$, Helen Lin ${ }^{1}$, Lee Honigberg ${ }^{1}$, Jin Y. Jin ${ }^{1}$ and Angelica Quartino ${ }^{1 *}$ (iD

\begin{abstract}
Background: Crenezumab, a fully humanized anti-beta-amyloid (Aß) immunoglobulin G4 (lgG4) monoclonal antibody, binds to both monomeric and aggregated forms of $A \beta$. We assessed the pharmacokinetics (PK)/ pharmacodynamics (PD) of crenezumab and its interaction with monomeric $A \beta(1-40)$ and $A \beta(1-42)$ peptides in serum/plasma and cerebrospinal fluid (CSF) samples from the phase II ABBY and BLAZE studies and the phase Ib GN29632 study.
\end{abstract}

Methods: In ABBY, BLAZE, and GN29632 studies, patients with mild-to-moderate AD were treated with either placebo or crenezumab (300 mg subcutaneously every 2 weeks [q2w], or $15 \mathrm{mg} / \mathrm{kg}, 30 \mathrm{mg} / \mathrm{kg}, 45 \mathrm{mg} / \mathrm{kg}, 60 \mathrm{mg} / \mathrm{kg}$, or $120 \mathrm{mg} / \mathrm{kg}$ intravenously q4w). Serum/plasma PK/PD analyses included samples from 131 patients who received crenezumab in all three studies. CSF PK/PD analyses included samples from 76 patients who received crenezumab in ABBY or BLAZE. The impact of baseline patient factors on A $\beta$ profiles was also evaluated.

Results: The serum concentration of crenezumab increased in a dose-proportional manner between 15 and 120 $\mathrm{mg} / \mathrm{kg} \mathrm{q} 4 \mathrm{w}$. Total monomeric plasma $A \beta(1-40)$ and $A \beta(1-42)$ levels significantly increased after crenezumab administration. The mean crenezumab CSF to serum ratio was $\sim 0.3 \%$ and was similar across dosing cohorts/routes of administration. No clear correlation was observed between crenezumab concentration and $A \beta(1-42)$ increase in CSF at week 69. The target-mediated drug disposition (TMDD) model described the observed plasma concentration-time profiles of crenezumab and $A \beta$ well. Elimination clearance $\left(C L_{e l}\right)$ and central volume of distribution $\left(V_{\text {cent }}\right)$ of crenezumab were estimated at $0.159 \mathrm{~L} /$ day and $2.89 \mathrm{~L}$, respectively, corresponding to a half-life of $\sim 20$ days. Subcutaneous bioavailability was estimated at $66.2 \%$.

Conclusions: Crenezumab PK was dose proportional up to $120 \mathrm{mg} / \mathrm{kg}$, with a half-life consistent with $\mathrm{lgG}$ monoclonal antibodies. Our findings provide evidence for peripheral target engagement in patients with mild-tomoderate AD. The study also showed that a model-based approach is useful in making inference on PK/PD relationship with unmeasured species such as free plasma $A \beta$ levels.

Trial registrations: ABBY: ClinicalTrials.gov, NCT01343966. Registered April 28, 2011. BLAZE: ClinicalTrials.gov, NCT01397578. Registered July 19, 2011. GN29632: ClinicalTrials.gov, NCT02353598. Registered February 3, 2015.

Keywords: Pharmacokinetics, PK/PD, Plasma beta-amyloid, Nonlinear mixed-effects modeling, Target-mediated drug disposition model

\footnotetext{
* Correspondence: quartino.angelica@gene.com

${ }^{1}$ Genentech, Inc., South San Francisco, CA 94080, USA

Full list of author information is available at the end of the article
}

(c) The Author(s). 2020 Open Access This article is distributed under the terms of the Creative Commons Attribution 4.0 International License (http://creativecommons.org/licenses/by/4.0/), which permits unrestricted use, distribution, and reproduction in any medium, provided you give appropriate credit to the original author(s) and the source, provide a link to the Creative Commons license, and indicate if changes were made. The Creative Commons Public Domain Dedication waiver (http://creativecommons.org/publicdomain/zero/1.0/) applies to the data made available in this article, unless otherwise stated. 


\section{Background}

Alzheimer's disease (AD) is the most common cause of dementia, thought to affect 47 million people worldwide [1]. Accumulations of beta-amyloid (A $\beta$ ) peptides and amyloid plaque deposition in the brain are characteristic of $\mathrm{AD}[2]$. $\mathrm{A} \beta$ peptides can exist as monomers or aggregated forms (soluble oligomers, fibers, and plaque), and although the extent to which different $\mathrm{A} \beta$ species contribute to the pathophysiology of $\mathrm{AD}$ remains uncertain, in vitro and ex vivo evidence suggests that soluble oligomers may be major drivers of neurotoxicity [3-5].

Crenezumab is a fully humanized anti-A $\beta$ immunoglobulin G4 (IgG4) monoclonal antibody (mAb) that binds to monomeric as well as aggregated forms of $A \beta$ $[6,7]$. In vitro, crenezumab has been shown to block $A \beta$ aggregation, promote disaggregation, and protect neurons from oligomer-induced cytotoxicity [6]. Completed clinical trials of crenezumab in patients with mild-to-moderate $\mathrm{AD}$ include the phase II ABBY (NCT01343966) and BLAZE (NCT01397578) studies [8, 9]. Despite these studies not meeting their primary endpoints, exploratory post hoc analyses of the effects of crenezumab in a subset of patients with very mild $A D$ in the high-dose $15 \mathrm{mg} / \mathrm{kg}$ intravenous (IV) cohort suggested the utility of testing earlier treatment of $\mathrm{AD}$ with higher doses of crenezumab [8]. Interim data from a phase Ib GN29632 study (NCT02353598) [10-12] supported further testing of higher doses of crenezumab. Two phase III studies (CREAD, NCT02670083; CREAD2, NCT03114657) investigated the efficacy and safety of crenezumab at a dose of $60 \mathrm{mg} / \mathrm{kg}$ IV every 4 weeks $(\mathrm{q} 4 \mathrm{w})$, i.e., fourfold higher than the high dose in phase II, compared with placebo in patients with early (prodromal-to-mild) AD [13, 14]. These studies were recently discontinued following a pre-planned interim analysis of CREAD, which indicated the study was unlikely to meet its primary endpoint; no safety signals were observed in this analysis and the overall safety profile was similar to that seen in previous trials [15]. A study of the efficacy and safety of crenezumab in individuals who carry the PSEN1 E280A autosomal-dominant mutation and do not meet the criteria for mild cognitive impairment due to $\mathrm{AD}$ or dementia due to $\mathrm{AD}$ and are, thus, in a preclinical phase of $\mathrm{AD}$ (autosomal-dominant AD) is ongoing [16].

Here we report the PK of crenezumab and its interaction with monomeric $A \beta(1-40)$ and $A \beta(1-42)$ peptides (peripheral target engagement pharmacodynamic (PD) biomarkers) as assessed in serum/plasma and cerebrospinal fluid (CSF) in samples from phase II ABBY and BLAZE studies and the phase Ib GN29632 study. Monomeric $A \beta(1-40)$ and $A \beta(1-42)$ peptides were evaluated in this analysis, as they can be measured reliably in plasma and CSF using automated high- precision immunoassays. While $\mathrm{A} \beta$ oligomers have also been measured successfully in CSF from the ABBY and BLAZE studies [17], it is technically challenging to measure those forms of $A \beta$ in plasma. PK/PD characteristics of mAbs such as crenezumab, and their interactions with target molecules, can be described by target-mediated drug disposition (TMDD) models, which take into account the binding affinity of the antibody for its target molecule and the resulting degradation/clearance of the antibody-target complex and as such can provide insights to unmeasured species such as free target concentrations. This is of high value as development of assays for free targets are often technically challenging. We constructed a TMDD model to describe crenezumab serum concentrations and plasma $A \beta(1-40)$ and $A \beta(1-42)$ peptide levels in patients treated with crenezumab to help quantitatively interpret observed interactions and simulate the concentration of unmeasured species, such as free plasma $A \beta$. In addition, plasma $A \beta$ levels have been reported to be influenced by baseline patient characteristics, e.g., age and renal function [18]; therefore, we also used this model to assess the impact of baseline patient characteristics on the $\mathrm{A} \beta$ profiles.

\section{Methods}

\section{Study design and subjects}

In this analysis, crenezumab PK and PD data, i.e., serum total crenezumab concentrations and plasma total monomeric $\mathrm{A} \beta(1-40)$ and $\mathrm{A} \beta(1-42)$ levels, collected from patients enrolled in the phase II ABBY and BLAZE studies and the phase Ib GN29632 study were used. The detailed methodology, study randomization, and sample size determination for the studies have been described previously (Table 1 ) $[8,9,12]$.

ABBY was a phase II, randomized, double-blind, placebo-controlled study designed to evaluate the safety and efficacy of crenezumab in patients with mild-tomoderate AD [8]. Patients received low-dose $300 \mathrm{mg}$ SC crenezumab or placebo q2w, or high-dose $15 \mathrm{mg} / \mathrm{kg}$ IV crenezumab or placebo $\mathrm{q} 4 \mathrm{w}$. To assess the potential for using a higher dose of crenezumab compared with phase I, part 2 of ABBY was preceded by a safety run-in (SRI) period (for SRI dosing schemes, see Table 1) [8].

BLAZE was a phase II, randomized, double-blind, placebo-controlled study designed to evaluate the effects of crenezumab on brain amyloid plaque load as assessed by florbetapir positron emission tomography (PET) and other biomarkers in patients with mild-to-moderate $\mathrm{AD}$ [9]. Patients were required to have evidence of elevated amyloid burden consistent with a diagnosis of AD. The study was conducted in two parts as described above for the ABBY study without the SRI period/cohort. Dosing 
Table 1 Overview of characteristics of included crenezumab studies

\begin{tabular}{|c|c|c|c|c|}
\hline Study & Phase & Design & Treatments & Subjects \\
\hline ABBY [8] & $\|$ & $\begin{array}{l}\text { Double-blind, placebo- } \\
\text { controlled, randomized, } \\
\text { parallel-group study }\end{array}$ & $\begin{array}{l}\text { Part 1: Low-dose } 300 \mathrm{mg} \text { SC crenezumab } \\
\text { q4w } \\
\text { Part 2: High-dose } 15 \mathrm{mg} / \mathrm{kg} \text { IV crenezumab } \\
\text { q4w } \\
\text { Placebo } \mathrm{q} 4 \mathrm{w} \\
\text { SRI: At least } 2 \text { monthly administrations of } \\
15 \mathrm{mg} / \mathrm{kg} \text { IV crenezumab or placebo }\end{array}$ & $\begin{array}{l}431 \text { patients with mild-to-moderate } A D \text { aged } 50-80 \\
\text { years were randomized 2:1 (crenezumab:placebo) } \\
\text { - Part 1: } 184 \text { patients } \\
\text { - Part 2: } 241 \text { patients } \\
\text { - SRI: } 13 \text { patients }\end{array}$ \\
\hline BLAZE [9] & $\|$ & $\begin{array}{l}\text { Double-blind, placebo- } \\
\text { controlled, randomized } \\
\text { study }\end{array}$ & $\begin{array}{l}\text { Part 1: Low-dose } 300 \mathrm{mg} \text { SC crenezumab } \\
\text { q4w } \\
\text { Part 2: High-dose } 15 \mathrm{mg} / \mathrm{kg} \mathrm{IV} \\
\text { crenezumab q4w } \\
\text { Placebo q4w }\end{array}$ & $\begin{array}{l}91 \text { A } 3 \text {-positive patients with mild-to-moderate AD } \\
\text { aged 50-80 years were randomized 2:1 } \\
\text { (crenezumab:placebo) } \\
\text { - Part 1: } 39 \text { patients } \\
\text { - Part 2: } 52 \text { patients }\end{array}$ \\
\hline $\begin{array}{l}\text { GN29632 } \\
{[10-12]}\end{array}$ & $\mathrm{lb}$ & $\begin{array}{l}\text { Double-blind, placebo- } \\
\text { controlled, randomized } \\
\text { study followed by } \\
\text { open-label extension }\end{array}$ & $\begin{array}{l}\text { Double-blind phase: } \\
\text { Cohort 1: } 30 \text { or } 45 \mathrm{mg} / \mathrm{kg} \text { IV crenezumab } \\
\text { q4w } \\
\text { Cohort 2: } 60 \mathrm{mg} / \mathrm{kg} \mathrm{IV} \mathrm{crenezumab} \mathrm{q4w} \\
\text { Cohort 3: } 120 \mathrm{mg} / \mathrm{kg} \text { IV crenezumab q4w } \\
\text { Placebo q4w } \\
\text { Open-label extension: } \\
\text { Cohort } 1 \text { and } 2 \text { could continue to receive } \\
\text { crenezumab at the originally assigned dose } \\
\text { Cohort } 3 \text { switched to } 60 \mathrm{mg} / \mathrm{kg} \text { q } 4 \mathrm{w} \\
\text { Placebo could cross over to crenezumab } \\
\text { at the originally assigned dose and } \\
60 \mathrm{mg} / \mathrm{kg} \text { if assigned to cohort } 1 \text { or } 3\end{array}$ & $\begin{array}{l}75 \text { patients with mild-to-moderate AD aged } 50-90 \\
\text { years were randomized 5:1 at each of the crenezumab } \\
\text { dosing levels, or placebo up to week 13: } \\
\text { - Cohort 1: } 30 \mathrm{mg} / \mathrm{kg}: 10 \text { patients } \\
\quad 45 \mathrm{mg} / \mathrm{kg}: 11 \text { patients } \\
\text { - Cohort 2: } 21 \text { patients } \\
\text { - Cohort 3: } 19 \text { patients } \\
71 \text { patients entered the open-label extension }\end{array}$ \\
\hline
\end{tabular}

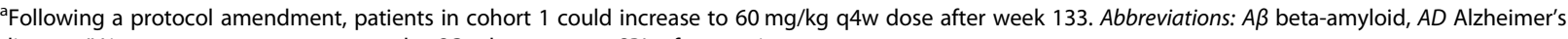
disease, $I V$ intravenous, $q 4 w$ every 4 weeks, SC subcutaneous, SRI safety run-in

regimens and patient numbers for both $\mathrm{ABBY}$ and BLAZE are described in Table 1.

In both ABBY (including the SRI period) and BLAZE, blood samples were collected for PK measurement of serum crenezumab concentrations at week 1 (on day 1, including a pre-dose baseline sample), at specified times throughout the treatment period (through week 69), during the efficacy and safety follow-up visits (weeks 73, 81, and 85), and at end-oftreatment/treatment discontinuation visits. For patients in the SC cohort, samples were collected prior to study drug administration on dosing days; for those in the IV cohort, samples were collected prior to study drug administration and $60 \mathrm{~min}$ after the end of infusion, unless otherwise specified. Blood samples for PD analysis were collected during the screening period and at the week 1 (day 1) visit, at specified times during the treatment period (through week 69), weeks 73 , 81 , and 85 of the safety follow-up visits, and at endof-treatment/treatment discontinuation visits. On dosing days, blood samples for PD analysis were collected prior to study drug administration. In ABBY, CSF samples were collected as an optional procedure at week 1 (day 1/baseline) and before study drug administration at week 69 (steady state). In BLAZE, CSF samples were collected from all patients at screening and prior to dosing at week 69 or at early termination/discontinuation, if necessary.
GN29632 was a phase Ib, multicenter, randomized, double-blind, placebo-controlled, parallel-group ascending dose study followed by an open-label extension (OLE) study. This study was designed to assess the safety, tolerability, and PK of crenezumab delivered at higher doses than those used in the phase II program. Patients were randomly assigned to one of the three cohorts and received between 30 and $120 \mathrm{mg} / \mathrm{kg}$ IV $\mathrm{q} 4 \mathrm{w}$ of crenezumab or placebo. Dosing regimens and patient numbers per cohort are detailed in Table 1. Blood samples for serum PK and plasma PD analyses were collected at baseline (week 1/day 1 ; pre-dose, $1 \mathrm{~min}$, and $60-90 \mathrm{~min}$ post-administration), week 1 /day 2 , week 1 /day 8 ( \pm 2 days), week 2 /day 15 ( \pm 2 days), week 5 ( \pm 2 days), week 9 ( \pm 2 days), week 13 ( \pm 2 days), week 21 ( \pm 2 days), at end of treatment, and at the start of the OLE study. Per protocol, all scheduled serum PK and plasma PD samples were obtained just prior to study drug administration and $60-90 \mathrm{~min}$ after the end of infusion.

All studies were conducted in accordance with the ethical principles of the Declaration of Helsinki and complied with Good Clinical Practice. A central investigational review board and individual site institutional review boards reviewed and provided approval for the protocols as well as informed consent forms. All subjects provided informed consent and consent for publication. 


\section{PK/PD assessments}

Total serum crenezumab concentrations were analyzed using a validated enzyme-linked immunosorbent assay with a lower limit of quantification of $0.05 \mu \mathrm{g} / \mathrm{mL}$ for serum and $0.012 \mu \mathrm{g} / \mathrm{mL}$ for CSF. Total monomeric plasma $A \beta(1-40)$ and $A \beta(1-42)$ levels (which correspond to free and crenezumab-bound $A \beta$ levels) were measured using a robust, non-commercial Elecsys ${ }^{\circ}$ drugtolerant prototype assay on the $\operatorname{cobas}^{\circ}$ e411 analyzer (Roche Diagnostics, Rotkreuz, Switzerland), with a lower limit of detection of $<2 \mathrm{pg} / \mathrm{mL}$ (both assays). For the $A B B Y$ study, we measured $A \beta$ levels only for the SRI cohort with the current assay system due to method availability, and only the data from that cohort (in addition to data from BLAZE and phase Ib studies) are included in subsequent analyses. Total CSF crenezumab concentrations were analyzed using a validated enzyme-linked immunosorbent assay (limit of detection $12.5 \mathrm{ng} / \mathrm{mL}$ ) as described previously [9]. Total $A \beta(1-42)$ in CSF was measured using the Elecsys ${ }^{\circ} \beta$-Amyloid (1-42) immunoassay commercially available from Roche Diagnostics (Penzberg, Germany), which was confirmed to be tolerant to the presence of crenezumab in the sample [19].

\section{PK/PD analysis}

Crenezumab PK and $A \beta$ kinetics from all randomized subjects who received at least one dose of study treatment (placebo or active) and had at least one postdose assessment of both $P K$ and $A \beta$ levels during the three studies were analyzed using nonlinear mixedeffects modeling with NONMEM (version 7.3., ICON Development Solutions, Ellicott City, MD, USA). In total, 1332 serum PK and 2203 plasma PD samples from 131 patients were used for the analysis.

A TMDD model with Michaelis-Menten approximation [20] was used to describe the observed serum concentrations of crenezumab, plasma concentrations of $A \beta(1-40)$ and $A \beta(1-42)$, and the PK/PD relationship (Fig. 1). Michaelis-Menten approximation was selected because crenezumab concentration is in excess of the $A \beta$ concentration at clinical doses and $A \beta$ concentration increases upon crenezumab administration [20].

A stepwise covariate model (SCM) building tool developed in Perl-speaks-NONMEM (PsN), version 4.7.0 [21] was used to assess the impact of baseline patient factors, including age at enrollment, sex, body weight, and glomerular filtration rate (GFR) on A $\beta$ profiles, with $p$ values of 0.01 and 0.005 as criteria for the forward selection and backward elimination, respectively.

For evaluating PK/PD relationships in CSF, 76 PK and 74. PD samples from 76 patients enrolled in ABBY and BLAZE studies and receiving active treatment were analyzed using descriptive statistics.

\section{Results}

Serum crenezumab concentration and plasma $A \beta(1-40)$ and $A \beta(1-42)$ levels after the first dose of crenezumab The serum PK profile of crenezumab showed a biphasic disposition over the 28-day period following the first dose (Fig. 2). The serum concentration of crenezumab increased in a dose-proportional manner between 15 and $120 \mathrm{mg} / \mathrm{kg} \mathrm{q} 4 \mathrm{w}$ doses.

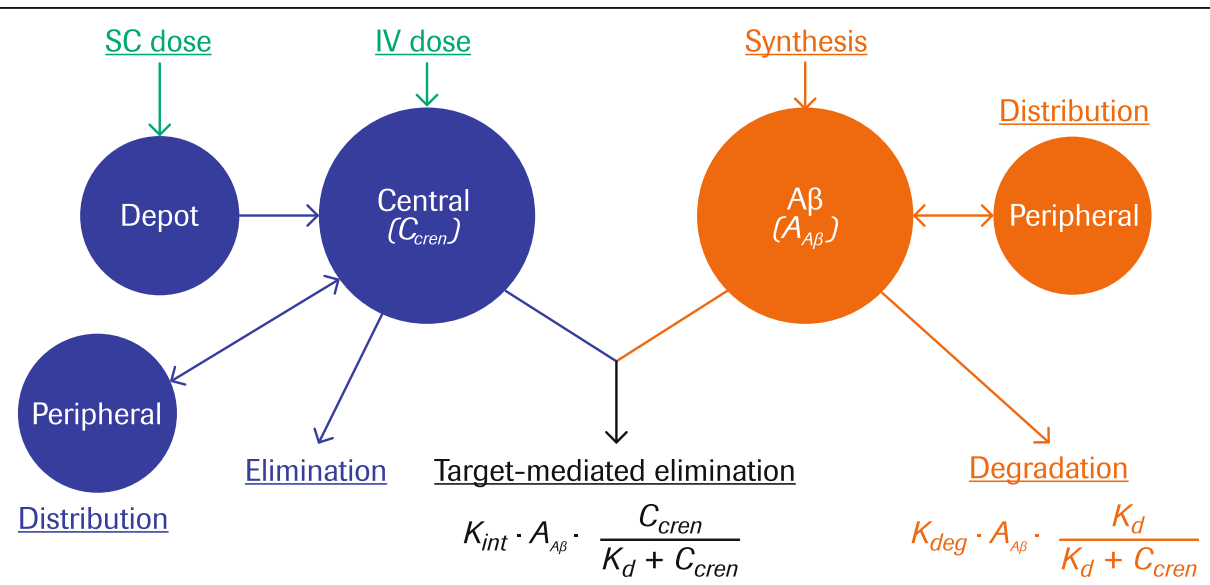

Fig. 1 Schematic representation of the TMDD model structure. According to Michaelis-Menten approximation, the drug-target complex is expected to be in quasi-equilibrium with the concentration of monoclonal antibody $>>$ target concentration. Abbreviations: $A_{A \beta}$ amount of betaamyloid, $A \beta$ beta-amyloid, $C_{c r e n}$ concentration of crenezumab, $N$ intravenous, $K_{d}$ equilibrium constant governing antibody-ligand binding, $k_{d e g}$ first-order rate constant for free ligand degradation, $k_{\text {int }}$ zero-order input rate constant for ligand, SC subcutaneous, TMDD target-mediated drug disposition 


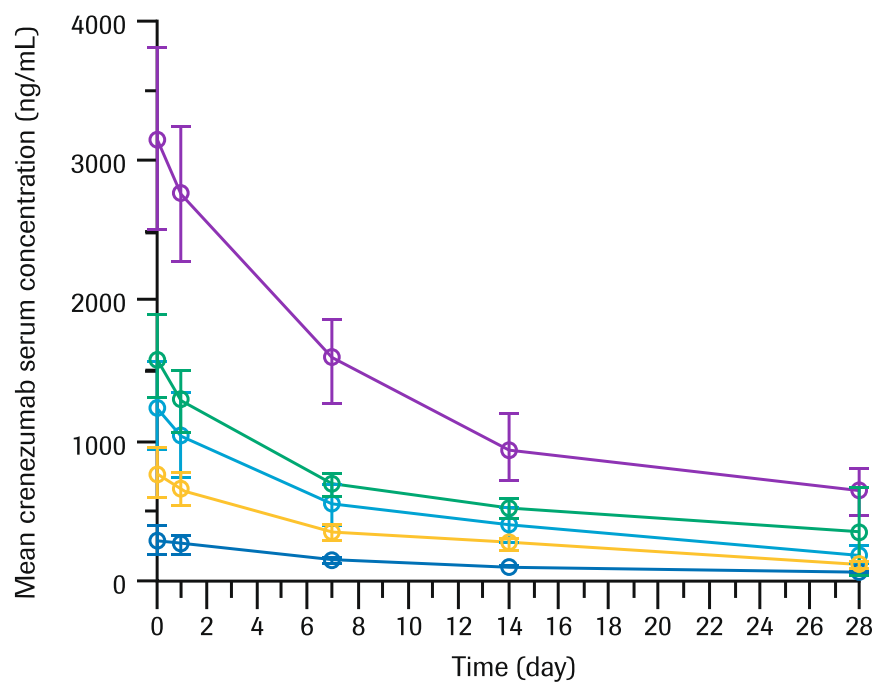

$$
\begin{aligned}
& \odot-15 \mathrm{mg} / \mathrm{kg} \\
& -30 \mathrm{mg} / \mathrm{kg} \\
& --45 \mathrm{mg} / \mathrm{kg} \\
& -60 \mathrm{mg} / \mathrm{kg} \\
& -120 \mathrm{mg} / \mathrm{kg}
\end{aligned}
$$

Fig. 2 Mean (SD) serum crenezumab concentrations after initial dose (weeks 1-5). Each line represents mean crenezumab serum concentration following IV administration; doses of $15 \mathrm{mg} / \mathrm{kg}$ (ABBY; BLAZE) and 30-120 mg/kg (GN29632 phase lb study). Abbreviations: IV intravenous, SD standard deviation

Total monomeric plasma $A \beta(1-40)$ and $A \beta(1-42)$ levels significantly increased after administration of crenezumab, demonstrating peripheral target engagement (Fig. 3). PD response was delayed compared with the time to peak crenezumab concentration and reached its maximum level 7-14 days after the initial dose (Fig. 3). Total plasma $A \beta$ levels increased in a dose-dependent, but not dose-proportional manner. Analyses of pre-dose serum crenezumab $\left(C_{\text {trough }}\right)$ and plasma $\mathrm{A} \beta$ suggest that the accumulation of total plasma $A \beta$ reached a plateau following crenezumab $120 \mathrm{mg} / \mathrm{kg} \mathrm{q} 4 \mathrm{w}$ dosing (Fig. 4).
CSF crenezumab concentrations and CSF $A \beta(1-42)$ levels The ratio of crenezumab detected in the CSF vs serum was consistent across dosing cohorts/routes of administration with a mean crenezumab CSF to serum ratio of $\sim 0.3 \%$. The mean (standard deviation) steady-state pre-dose crenezumab concentrations in CSF were low $(0.19[0.14] \mu \mathrm{g} / \mathrm{mL}$ in the $300 \mathrm{mg} \mathrm{SC}$ cohort; $0.25[0.12] \mu \mathrm{g} / \mathrm{mL}$ in the $15 \mathrm{mg} / \mathrm{kg}$ IV cohorts). As described previously for the BLAZE study [9], there was a significant increase in CSF total $\mathrm{A} \beta(1-42)$ concentrations in patients treated with

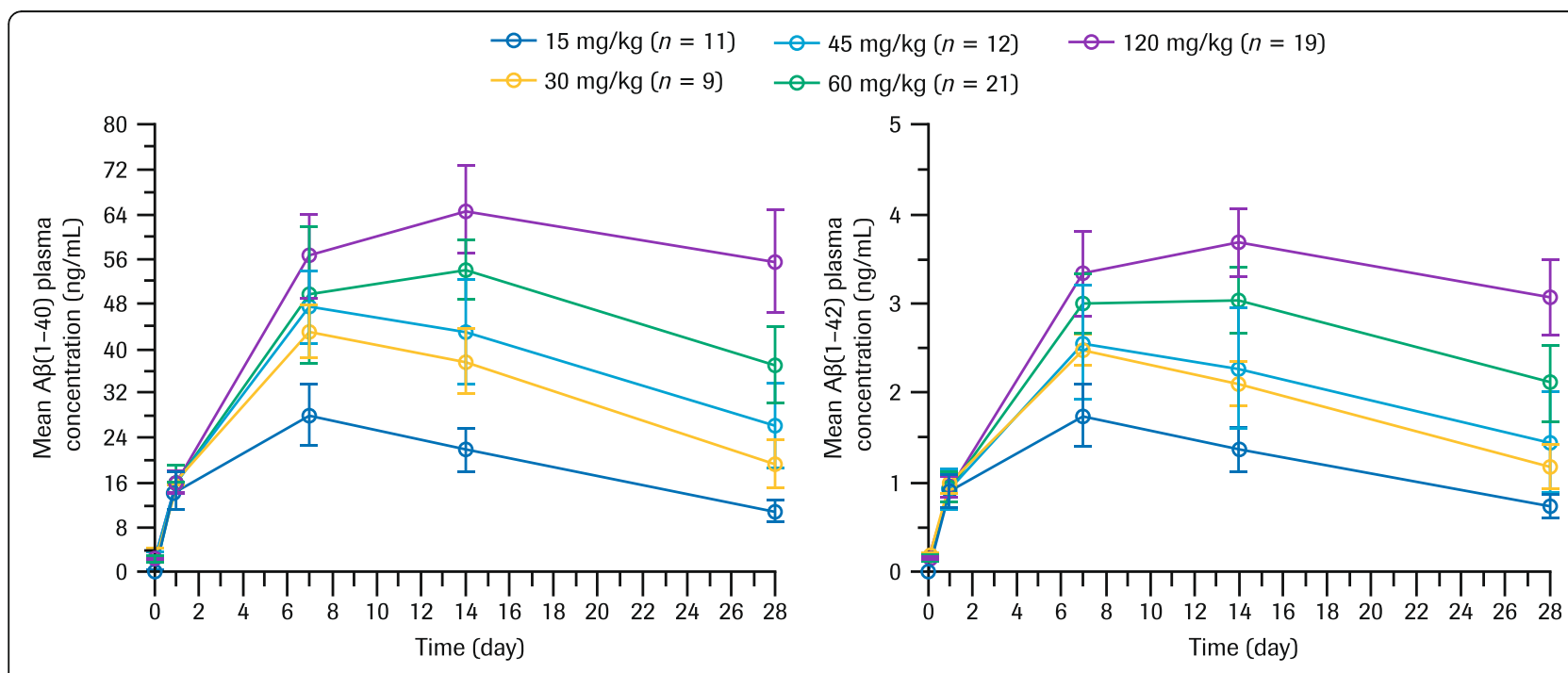

Fig. 3 Mean (SD) total plasma $A \beta(1-40)$ and $A \beta(1-42)$ concentrations after initial dose (weeks 1-5). Total number of patients included =72. Each line represents mean total $A \beta(1-40)$ or $A \beta(1-42)$ plasma concentration following IV administration; data shown are from the phase II ABBY study (SRI cohort) for $15 \mathrm{mg} / \mathrm{kg}$ dose and phase lb GN29632 for 30-120 mg/kg doses. Abbreviations: A $\beta$ beta-amyloid, $I V$ intravenous, SD standard deviation, SRI safety run-in 


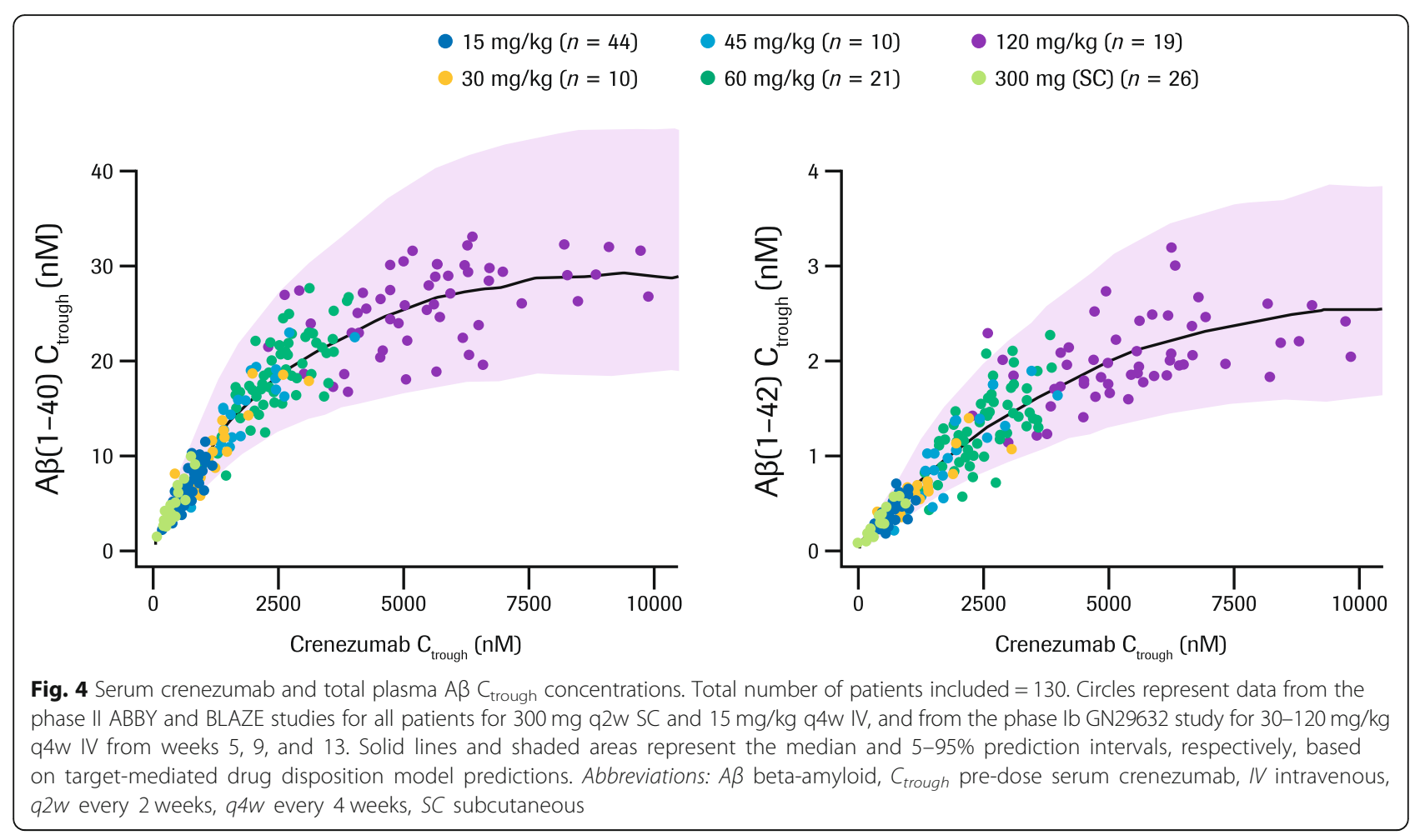

crenezumab. In the low-dose SC cohort, CSF A $\beta(1-42)$ mean change from baseline was $-52.11 \mathrm{pg} / \mathrm{mL}$ in the placebo arm, while in the crenezumab arm mean change from baseline was $+74.90 \mathrm{pg} / \mathrm{mL}$ (crenezumab vs placebo difference of $127.01 \mathrm{pg} / \mathrm{mL}, p=0.001$ ). In the high-dose IV cohort, CSF A $\beta(1-42)$ mean change from baseline was $-86.65 \mathrm{pg} / \mathrm{mL}$ in the placebo arm, whereas in the crenezumab arm mean change from baseline was $+7.86 \mathrm{pg} / \mathrm{mL}$ (crenezumab vs placebo difference of $94.51 \mathrm{pg} / \mathrm{mL}, p=0.022$ ).

There was no clear PK/PD correlation between steadystate pre-dose CSF crenezumab levels and CSF A $\beta(1-42)$ changes at week 69 (Fig. 5). The crenezumab serum and CSF concentrations in BLAZE were similar to those in ABBY $[8,9]$.

\section{Model-based analysis of serum crenezumab and plasma $A \beta(1-40)$ and $A \beta(1-42)$ concentrations}

The final TMDD model with Michaelis-Menten approximation (Fig. 1) described the observed profiles of crenezumab and $A \beta$ well (Fig. 6). Overall, the PK/PD parameter values obtained through the nonlinear mixedeffects modeling were reasonable, with relative standard error of less than $10 \%$ for most fixed effects (Table 2). Estimated baseline plasma $A \beta(1-40)$ and $A \beta(1-42)$ values were $142 \mathrm{pM}$ and $5.98 \mathrm{pM}$, respectively, and between-subject variability (BSV) values were $8.3 \%$ and $13.8 \%$, respectively. The estimated equilibrium constant governing antibody-ligand binding $\left(K_{\mathrm{d}}\right)$ levels for $\mathrm{A} \beta(1-40)$ and $\mathrm{A} \beta(1-42)$ were $12 \mathrm{nM}$ and $9.37 \mathrm{nM}$, respectively. Crenezumab exhibited dose-proportional PK with the estimated elimination clearance $\left(\mathrm{CL}_{\mathrm{el}}\right)$ and central volume of distribution $\left(V_{\text {cent }}\right)$ of $0.159 \mathrm{~L} /$ day and $2.89 \mathrm{~L}$, respectively, which are consistent with typical values for IgG mAbs [22] and correspond to a half-life $\left(t_{1 / 2}\right)$ of $\sim 20$ days. SC bioavailability $\left(F_{\mathrm{sc}}\right)$ was estimated at $66.2 \%$. Estimated intrinsic clearance of the crenezumab-A $\beta$ complex $\left(\mathrm{CL}_{\text {int }}\right)$ was $1.01 \mathrm{~L} /$ day, sixfold faster than that of crenezumab alone (Table 2).

\section{Analysis of impact of patient baseline characteristics on crenezumab and $A \beta$ kinetics in plasma and serum}

We evaluated the effects of selected patient characteristics (subsequently referred to as covariates) on crenezumab and plasma $A \beta$ kinetics. Body weight was a statistically significant covariate for crenezumab PK $\left(\mathrm{CL}_{\mathrm{e}}, \mathrm{CL}_{\text {int }}\right.$, and $\left.V_{\text {cent }}\right)$, age and GFR were statistically significant covariates for baseline plasma $A \beta$ levels, and sex was a statistically significant covariate for degradation rate constant of plasma $\mathrm{A} \beta\left(K_{\mathrm{deg}}\right)$. Estimated $\mathrm{BSV}$ of $\mathrm{CL}_{\mathrm{el}}$ and $V_{\text {cent }}$ decreased from 25 to $19 \%$ and 23 to $18 \%$, respectively, after incorporating the effect of body weight, although it did not appear to be a major source of the observed BSV; between $90 \%$ of the observed range $(52.4-95.9 \mathrm{~kg})$, differences in area under the curve (AUC) and peak concentration $\left(C_{\max }\right)$ were 1.1-fold higher (higher exposure with smaller body weight) (Fig. 7). After incorporating the effect of age and GFR, 


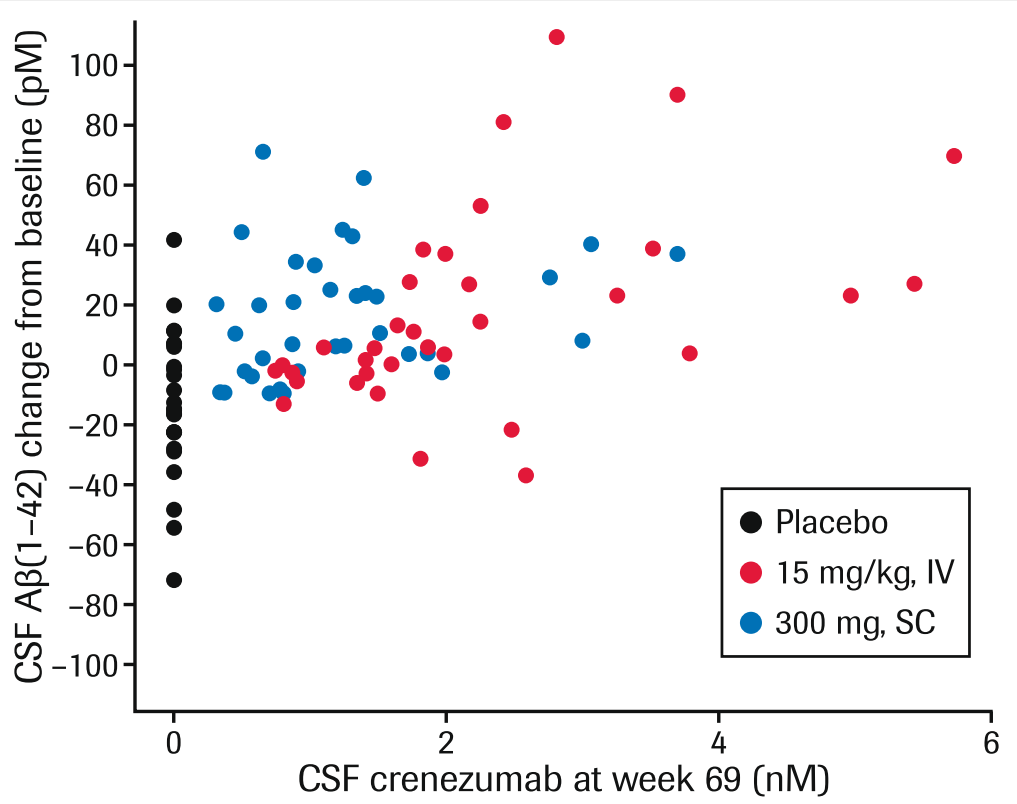

Fig. 5 Steady-state pre-dose crenezumab concentration and AB(1-42) change from baseline in CSF at week 69. Data shown are from the phase II ABBY and BLAZE studies for patients enrolled in $300 \mathrm{mg}$ q2w SC or $15 \mathrm{mg} / \mathrm{kg}$ q4W IV cohorts. Abbreviations: A 3 beta-amyloid, CSF cerebrospinal fluid, $I V$ intravenous, q2W every 2 weeks, $94 \mathrm{~W}$ every 4 weeks, SC subcutaneous

estimated BSV for baseline levels of $\mathrm{A} \beta(1-40)$ and $\mathrm{A} \beta(1-42)$ decreased from 11 to $8.3 \%$ and 16 to $14 \%$, respectively. Differences in baseline levels of $A \beta(1-40)$ and $A \beta(1-42)$ in $90 \%$ of the observed range of GFR ( 94.0 to $46.5 \mathrm{~mL} / \mathrm{min} / 1.73 \mathrm{~m}^{2}$ ) were 1.2 - and 1.25 -fold higher in patients with smaller GFR. Differences in baseline levels of $A \beta(1-40)$ in $90 \%$ of the observed range of age (54-82 years) were 1.1-fold higher in patients with higher age (Fig. 7). Incorporating the effect of sex on $K_{\text {deg }}$ decreased BSV from 19 to $18 \%$.

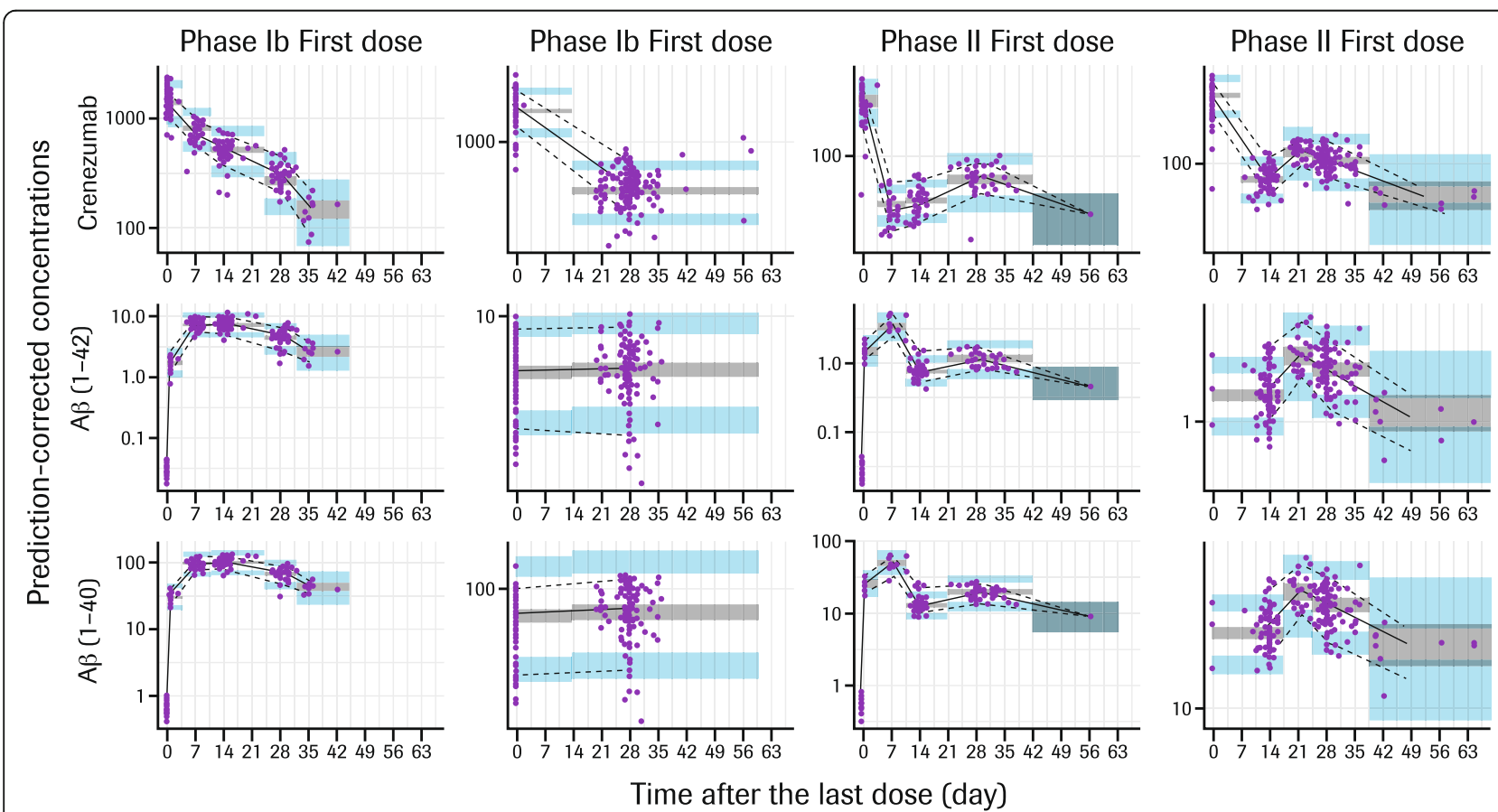

Fig. 6 Prediction-corrected visual predictive check plots. Phase lb, data from GN29632 study; phase II, data from ABBY and BLAZE studies. Circles represent observed data. Solid and dashed lines represent median and 90th percentiles of observed data, respectively. Gray and blue shaded areas represent simulated $90 \%$ prediction interval of median and 90 th percentiles, respectively. Abbreviations: $A \beta$ beta-amyloid, $P h$ phase 
Table 2 Estimated PK/PD parameters determined using nonlinear mixed-effects modeling

\begin{tabular}{|c|c|c|c|c|}
\hline Parameter & Estimate & RSE (\%) & BSV (CV\%) & RSE (\%) \\
\hline \multicolumn{5}{|l|}{ Crenezumab } \\
\hline $\mathrm{CL}_{\mathrm{el}}(\mathrm{L} /$ day) & 0.159 & 3.0 & 19.1 & 8.4 \\
\hline $\mathrm{CL}_{\text {int }}(\mathrm{L} /$ day $)$ & 1.01 & 5.8 & 15.3 & 25 \\
\hline$V_{\text {cent }}(\mathrm{L})$ & 2.89 & 3.4 & 18.3 & 8.8 \\
\hline$V_{\text {periph }}(L)$ & 1.84 & 10 & 75.2 & 9.7 \\
\hline$Q$ (L/day) & 0.142 & 4.8 & - & - \\
\hline$F_{S C}(\%)$ & 66.2 & 3.9 & - & - \\
\hline$K_{a}$ (/day) & 0.161 & 6.4 & - & - \\
\hline$K_{d} A \beta(1-40)(n M)$ & 12.0 & 3.0 & $13.6^{\mathrm{a}}$ & 12 \\
\hline$K_{d} A \beta(1-42)(n M)$ & 9.37 & 2.5 & $13.6^{\mathrm{a}}$ & 12 \\
\hline BWT (kg) on $\mathrm{CL}_{\mathrm{el}}$ & 0.835 & 12 & - & - \\
\hline BWT (kg) on $\mathrm{CL}_{\text {int }}$ & 0.474 & 42 & - & - \\
\hline BWT (kg) on $V_{\text {cent }}$ & 0.725 & 17 & - & - \\
\hline \multicolumn{5}{|l|}{$A \beta(1-40)$} \\
\hline Baseline (pM) & 142 & 1.3 & 8.3 & 10 \\
\hline$K_{\text {deg }}(/$ day $)$ & 114 & 5.7 & $17.9^{\mathrm{a}}$ & 12 \\
\hline Q (L/day) & 8.72 & 31 & - & - \\
\hline$V_{\text {periph }}(L)$ & 3.77 & 11 & - & - \\
\hline Age (year) on baseline & 0.0037 & 27 & & \\
\hline GFR $\left(\mathrm{mL} / \mathrm{min} / 1.73 \mathrm{~m}^{2}\right)$ on baseline & -0.0035 & 20 & & \\
\hline Sex (male) on $K_{\text {deg }}{ }^{b}$ & -0.16 & 36 & & \\
\hline \multicolumn{5}{|l|}{$A \beta(1-42)$} \\
\hline Baseline (pM) & 5.98 & 1.7 & 13.8 & 9.9 \\
\hline$K_{\text {deg }}(/$ day $)$ & 287 & 6.5 & $17.9^{\mathrm{a}}$ & 12 \\
\hline$Q$ (L/day) & 229 & 15 & - & - \\
\hline$V_{\text {periph }}(\mathrm{L})$ & 8.19 & 7.8 & - & - \\
\hline GFR $\left(\mathrm{mL} / \mathrm{min} / 1.73 \mathrm{~m}^{2}\right)$ on baseline & -0.0048 & 22 & & \\
\hline Sex (male) on $K_{\text {deg }}{ }^{b}$ & -0.16 & 36 & & \\
\hline
\end{tabular}

Patient factors are incorporated as the exponential and linear form on the parameters for crenezumab and A $\beta$, respectively. ${ }^{\mathrm{a}} \mathrm{Same} B S \mathrm{~V}$ was used on $\mathrm{A} \beta(1-40)$ and

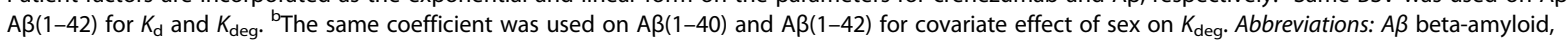
$B S V$ between-subject variability, $B W T$ body weight, $C L_{e l}$ elimination clearance (of crenezumab), $C L_{\text {int }}$ intrinsic clearance (of crenezumab- $A \beta$ complex), $C V$ coefficient of variation, $F_{S C}$ subcutaneous bioavailability, GFR glomerular filtration rate, $K_{a}$ absorption rate constant, $K_{d}$ equilibrium constant governing antibody-ligand binding, $K_{\text {deg }}$ degradation rate constant, $P D$ pharmacodynamics, $P K$ pharmacokinetics, $Q$ inter-compartment clearance, $R S E$ relative standard error, $V_{c e n t}$ central volume of distribution, $V_{\text {periph }}$ peripheral distribution volume

\section{Simulations of the effect of varying crenezumab doses on free and bound $A \beta$ kinetics based on the developed PK/PD model}

Crenezumab was detected in a large excess compared with plasma A $\beta$ levels (approximately 150-fold difference at steady-state $C_{\text {trough }}$ for $60 \mathrm{mg} / \mathrm{kg}$ dose); therefore, the crenezumab in serum was predominantly free. As may therefore be expected, the modeling data suggested that plasma $A \beta$ was predominantly bound (Fig. 8). The reduction in free plasma A $\beta$ levels associated with crenezumab treatment was better maintained at higher doses, even after the increase in total $\mathrm{A} \beta$ level had plateaued.

\section{Discussion}

In this pooled analysis of data from the phase II ABBY and BLAZE studies and the phase Ib GN29632 study, we showed that the PK of crenezumab in patients with mild-to-moderate $\mathrm{AD}$ was dose proportional across the dose range tested $(15-120 \mathrm{mg} / \mathrm{kg}$ q4w IV and $300 \mathrm{mg}$ $\mathrm{q} 2 \mathrm{w} \mathrm{SC})$ and was characterized by clearance and $t_{1 / 2}$ values expected of IgG mAbs $\left(0.159 \mathrm{~L} /\right.$ day and $t_{1 / 2} \sim 20$ days, respectively) (Table 2) [22]. Body weight was shown to influence the elimination clearance of crenezumab $\left(\mathrm{CL}_{\mathrm{el}}\right)$, intrinsic clearance of crenezumab-A $\beta$ complex $\left(\mathrm{CL}_{\text {int }}\right)$, and central distribution volume $\left(V_{\text {cent }}\right)$, all of which increased with increasing body weight (Fig. 7). These 

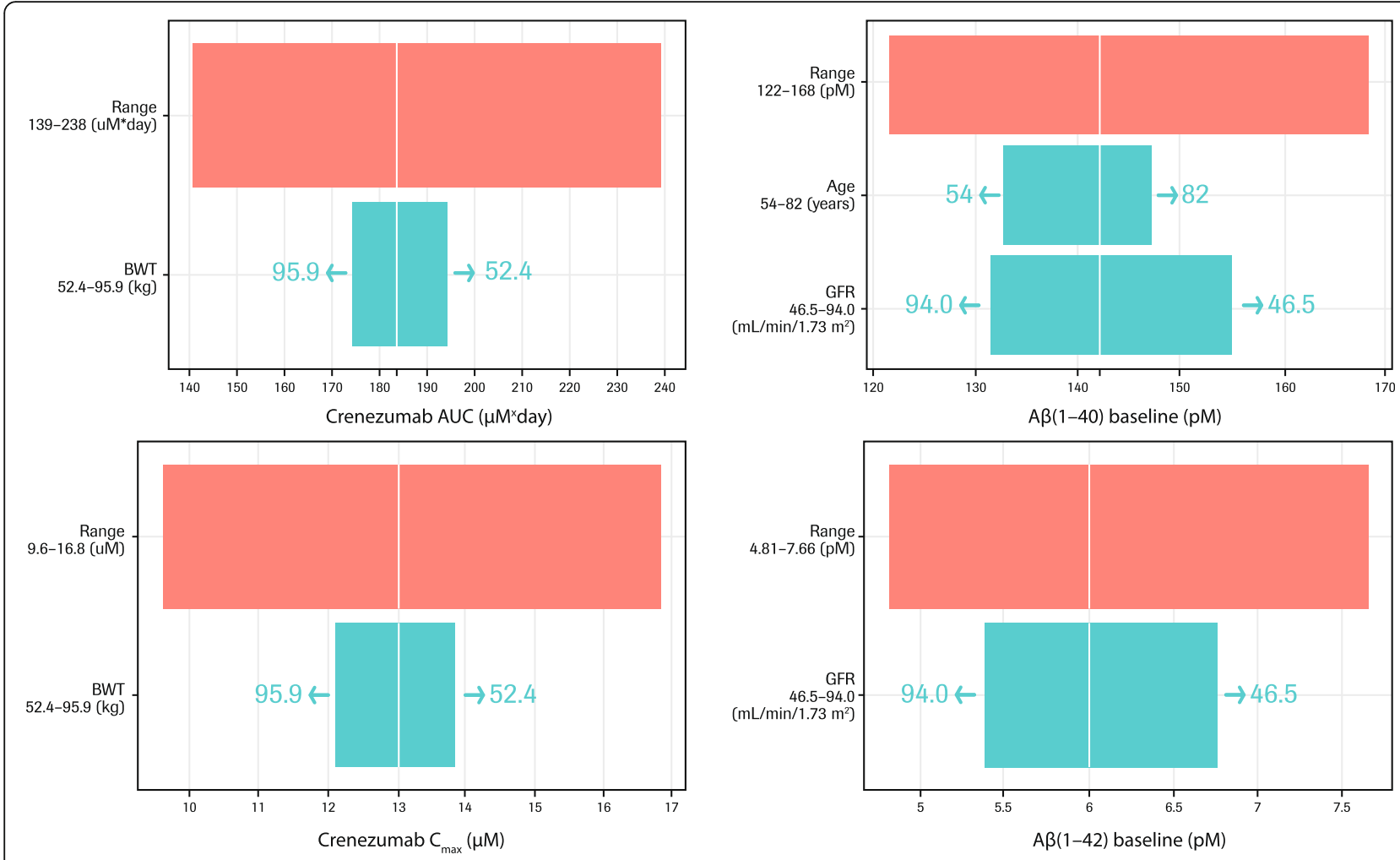

Fig. 7 Predicted impact of patient baseline characteristics on PK profile of crenezumab and plasma A levels. White vertical line refers to the predicted parameters for a 72 -year-old male, weighing $72.3 \mathrm{~kg}$, with a GFR of $72.5 \mathrm{~mL} / \mathrm{min} / 1.73 \mathrm{~m}^{2}$ after a crenezumab $60 \mathrm{mg} / \mathrm{kg} \mathrm{IV}$ dose. Red bar depicts the 5th-95th percentile crenezumab exposure (left column) or A levels (right column) range across the entire population. Green bar represents the influence of a single covariate on the predicted parameters. The upper and lower values for each covariate represent $90 \%$ of the observed covariate range in the population. Abbreviations: $A \beta$ beta-amyloid, $A U C$ area under the curve, BWT body weight, $C_{\text {max }}$ peak concentration, GFR glomerular filtration rate, $N$ intravenous, $P K$ pharmacokinetics

findings are consistent with the results observed for other therapeutic IgG molecules that exhibit linear kinetics in humans [22].

Total plasma $A \beta(1-40)$ and $A \beta(1-42)$ levels increased significantly following each administration of crenezumab demonstrating peripheral target engagement of monomeric $A \beta(1-40)$ and $A \beta(1-42)$. The increase in total $A \beta(1-40)$ and $A \beta(1-42)$ levels can be attributed to slower elimination of crenezumab- $A \beta$ complex than free $A \beta(1-40)$ and $A \beta(1-42): 0.36$ vs 114 [A $\beta(1-40)]$ or $287[A \beta(1-42)]$ on day 1 . The observed increase in total plasma $A \beta$ levels was dose dependent but not dose proportional and reached a plateau with the $120 \mathrm{mg} / \mathrm{kg}$ q4w IV dose. A TMDD model developed to characterize the observed serum crenezumab concentrations, plasma $A \beta(1-40)$ and $A \beta(1-42)$ levels, and the PK/PD relationship between them, successfully described the observed data, including the non-dose-proportional increase in plasma $A \beta$ levels. This model suggested that reductions in free $A \beta$ levels associated with crenezumab dosing are better maintained at higher doses, even after the total plasma $A \beta$ levels had plateaued (Fig. 8).
Our analysis suggested that age and GFR explain some of the BSV in baseline A $\beta$ levels. This is consistent with a previous study by Toledo and colleagues [18] who analyzed baseline $A \beta$ measures in 715 subjects from the Alzheimer's Disease Neuroimaging Initiative (ADNI) database (http://www.adni-info.org/index) and reported that age, platelet count, total protein, and creatinine concentration were independent predictors of baseline $A \beta(1-40)$ and $A \beta(1-42)$ levels, explaining $12.1 \%$ and $12.9 \%$ of the observed variability in the respective parameters [18]. The model estimated $K_{\mathrm{d}}$ of crenezumab against $A \beta(1-40)$ and $A \beta(1-42)$ were similar to each other. This is consistent with in vitro observation that crenezumab has similar binding affinity to these two $A \beta$ species $(\sim 10 \mathrm{nM})$ [F. Hoffmann-La Roche Ltd.; data on file]. Patient factors, such as age or sex, were not identified as significant covariates for $K_{\mathrm{d}}$, suggesting that the binding of crenezumab to $A \beta$ is independent of currently evaluated patient factors.

The PK/PD data from this study provide evidence of peripheral target engagement by crenezumab at evaluated dose levels. This complements the target 


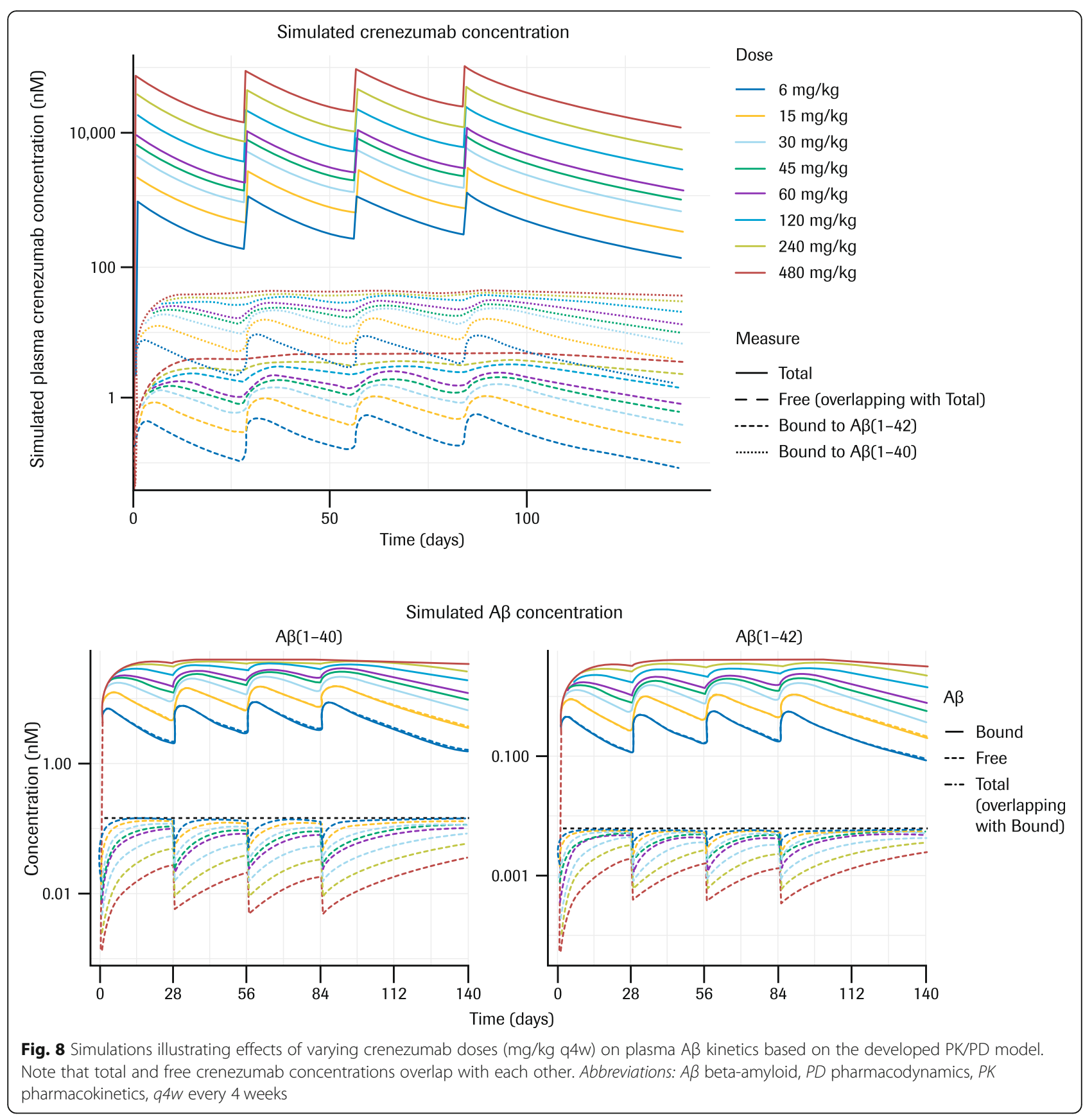

engagement in the central nervous system previously suggested in the phase II ABBY and BLAZE studies through the increase of total monomeric $A \beta(1-42)$ in CSF of patients with mild-to-moderate AD treated with crenezumab [8]. The increase in total monomeric $A \beta(1-42)$ is likely due to slower elimination of crenezumab- $A \beta$ complex. We further evaluated relationships between crenezumab concentration and $A \beta(1-42)$ increase in CSF, but no clear correlation was observed (Fig. 5), which could be due to limited ranges of evaluable doses and high variability between patients for demonstrating exposure-response relationships in CSF. The concentration of crenezumab in CSF was much higher than the concentration of $A \beta$, yet still much lower than in serum (approximately $0.3 \%$ of serum). This suggests that a wider dose range is needed to be able to quantify the exposure-response relationship in the central nervous system.

The PK/PD simulation provided several important insights. Firstly, the simulation showed that circulating crenezumab is predominantly unbound. This indicates that the transfer of crenezumab to peripheral organs and 
the central nervous system is likely not influenced by its binding to $A \beta$. The low concentration of crenezumab-A $\beta$ complex, compared with total crenezumab, also suggests that the transfer of the binding complex is unlikely to serve as a new source of $A \beta$ for peripheral organs including the central nervous system.

Another interesting observation is that predicted free $A \beta$ levels continued to decrease with increasing dose, even after the accumulation of total $A \beta$ reached a plateau (Fig. 8), suggesting that total $A \beta$ change may not be fully reflective of actual drug effect. The reason for this apparent discrepancy between total and free $A \beta$ profiles is that accumulation of total $A \beta$ is due to slower elimination of crenezumab- $A \beta$ complex than free $A \beta$. Therefore, once the crenezumab- $A \beta$ complex becomes the predominant species of total $A \beta$, there will be no further increase in total $A \beta$ with increased crenezumab dose. In contrast, binding of crenezumab to residual free $\mathrm{A} \beta$ can still occur with a higher free crenezumab concentration. Additionally, since analytical quantification of free $A \beta$ is technically challenging due to changing levels of bound vs free $A \beta$ in vitro after CSF collection that might differ from the levels in vivo, the model proposed in the current study could be a promising tool to integrate available information, such as total $A \beta$ levels, and provide further insights on the kinetics of unmeasured species such as free $A \beta$.

\section{Conclusion}

In this study, we showed that crenezumab PK was dose proportional at doses between 15 and $120 \mathrm{mg} / \mathrm{kg}$ with a $t_{1 / 2}$ consistent with IgG mAbs, and provided evidence of peripheral target engagement in patients with mild-tomoderate $\mathrm{AD}$, based on data pooled from three clinical trials of crenezumab (two phase II studies; one phase Ib study). We also observed dose-dependent increases in total monomeric $A \beta(1-42)$ levels in CSF; however, exposure-response relationships need to be further evaluated at higher doses and in larger studies. We demonstrated how a TMDD model can be used to integrate available information, such as the serum PK characteristics of crenezumab and the plasma total $A \beta$ levels, and to make inferences to unmeasured species such as free A $\beta$ levels.

\footnotetext{
Abbreviations

$A_{A B}$ : Amount of beta-amyloid; AD: Alzheimer's disease; ADNI: Alzheimer's Disease Neuroimaging Initiative; AUC: Area under the curve; $A \beta$ : Betaamyloid; BSV: Between-subject variability; BWT: Body weight;

$C_{\text {cren: }}$ Concentration of crenezumab; $\mathrm{CL}_{e}$ : Elimination clearance; $\mathrm{CL}_{\text {int }}$ : Intrinsic clearance; $C_{\max }$ : Peak concentration; CSF: Cerebrospinal fluid; $C_{\text {trough: }}$ Pre-dose serum crenezumab; CV: Coefficient of variation; $F_{\text {sc: }}$ SC bioavailability; GFR: Glomerular filtration rate; IgG: Immunoglobulin G; IV: Intravenous; $K_{\mathrm{a}}$ : Absorption rate constant; $K_{\mathrm{d}}$ : Estimated equilibrium constant governing antibody-ligand binding; $K_{\text {deg }}$ : Degradation rate constant; $K_{\text {int }}$ : Zero-order input rate constant for ligand; mAb: Monoclonal antibody; OLE: Open-label extension; PD: Pharmacodynamics; PET: Positron emission tomography;
}

PK: Pharmacokinetics; Q: Inter-compartment clearance; q2w: Every 2 weeks; q4w: Every 4 weeks; RSE: Relative standard error; SC: Subcutaneous; SCM: Stepwise covariate model; SD: Standard deviation; SRI: Safety run-in; $t_{1 / 2}$ : Half-life; TMDD: Target-mediated drug disposition; $V_{\text {cent: }}$ Central volume of distribution; $V_{\text {periph: }}$ Peripheral distribution volume

\section{Acknowledgements}

Crenezumab was discovered and is being developed, in collaboration with AC Immune SA, Lausanne, Switzerland. Medical writing support for the development of this manuscript was provided by Jonathan Plumb, PhD, of Bioscript Medical, Macclesfield, UK, and Rachel Johnson, PhD, and Helen Singleton, PhD, of Health Interactions, funded by F. Hoffmann-La Roche Ltd. COBAS and Elecsys are trademarks of Roche.

\section{Authors' contributions}

All authors were involved in drafting the work or revising it critically for important intellectual content. All authors have read and approved the final version of the manuscript and agree both to be personally accountable for the author's own contributions and to ensure that questions related to the accuracy or integrity of any part of the work, even ones in which the author was not personally involved, are appropriately investigated, resolved, and the resolution documented in the literature. KY contributed to the conception and design of the work, analysis and interpretation of the data, drafting of the work, and substantial revisions of the work. AM contributed to the analysis of the data and drafting part of the work. TB contributed to the design of the work and acquisition and interpretation of data. SO contributed to the acquisition and interpretation of the data and revisions of the manuscript. $\mathrm{HL}$ contributed to the acquisition and interpretation of the data. LH contributed to the conception of the work and acquisition and interpretation of the data. JYJ contributed to the conception of the work. AQ contributed to the conception and design of the work, acquisition, analysis and interpretation of the data, reviewing and editing of the work.

\section{Funding}

This study was funded by F. Hoffmann-La Roche Ltd. The study sponsor was responsible for the overall study management, drug supply, data management, statistical analysis, PK and PD analysis, and the drug safety process. The study sponsor was involved in the design of the study, data analysis and interpretation, and in writing the manuscript.

\section{Availability of data and materials}

Qualified researchers may request access to individual patient-level data through the clinical study data request platform (www.clinicalstudydatarequest.com). Further details on Roche's criteria for eligible studies are available here: https://clinicalstudydatarequest.com/Study-Sponsors/Study-SponsorsRoche.aspx. For further details on Roche's Global Policy on the Sharing of Clinical Information and how to request access to related clinical study documents, see here: https://www.roche.com/research_and_development/who_ we_are_how_we_work/clinical_trials/our_commitment_to_data_sharing.htm.

\section{Ethics approval and consent to participate}

All studies were conducted in accordance with the ethical principles of the Declaration of Helsinki and complied with Good Clinical Practice. A central investigational review board and individual site institutional review boards reviewed and provided approval for the protocols as well as informed consent forms. No modifications were made to the protocol after receipt of the Independent Ethics Committee approval. All subjects provided informed consent and consent for publication.

\section{Consent for publication}

Not applicable.

\section{Competing interests}

$K Y, A M, T B, S O, H L, L H, J Y J$, and $A Q$ are full-time employees of F. HoffmannLa Roche Ltd/Genentech, Inc., and hold stocks in F. Hoffmann-La Roche Ltd/Genentech, Inc.

\section{Author details}

${ }^{1}$ Genentech, Inc., South San Francisco, CA 94080, USA. ${ }^{2}$ F. Hoffmann-La Roche Ltd, Basel, Switzerland. 
Received: 23 August 2019 Accepted: 5 January 2020

Published online: 22 January 2020

\section{References}

1. Alzheimer's Disease International. World Alzheimer Report 2016 - Summary sheet: improving healthcare for people living with dementia. Coverage, quality and costs now and in the future. https://www.alz.co.uk/research/ worldalzheimerreport2016sheet.pdf. Accessed 8 July 2019.

2. Hardy J, Selkoe DJ. The amyloid hypothesis of Alzheimer's disease: progress and problems on the road to therapeutics. Science. 2002;297:353-6.

3. Haass C, Selkoe DJ. Soluble protein oligomers in neurodegeneration: lessons from the Alzheimer's amyloid beta-peptide. Nat Rev Mol Cell Biol. 2007:8:101-12.

4. Benilova I, Karran E, De Strooper B. The toxic A $\beta$ oligomer and Alzheimer's disease: an emperor in need of clothes. Nat Neurosci. 2012;15:349-57.

5. Wang ZX, Tan L, Liu J, Yu JT. The essential role of soluble A oligomers in Alzheimer's disease. Mol Neurobiol. 2016;53:1905-24.

6. Adolfsson O, Pihlgren $\mathrm{M}$, Toni $\mathrm{N}$, Varisco $\mathrm{Y}$, Buccarello AL, Antoniello $\mathrm{K}$, et al. An effector-reduced anti- $\beta$-amyloid $(A \beta)$ antibody with unique a $\beta$ binding properties promotes neuroprotection and glial engulfment of $A \beta$. J Neurosci. 2012;32:9677-89.

7. Ultsch M, Li B, Maurer T, Mathieu M, Adolfsson O, Muhs A, et al. Structure of crenezumab complex with $A \beta$ shows loss of $\beta$-hairpin. Sci Rep. 2016;6:39374.

8. Cummings JL, Cohen S, Van Dyck CH, Brody M, Curtis C, Cho W, et al. ABBY: a phase 2 randomized trial of crenezumab in mild to moderate Alzheimer disease. Neurology. 2018;90:e1889-97.

9. Salloway S, Honigberg LA, Cho W, Ward M, Friesenhahn M, Brunstein F, et al. Amyloid positron emission tomography and cerebrospinal fluid results from a crenezumab anti-amyloid-beta antibody double-blind, placebocontrolled, randomized phase II study in mild-to-moderate Alzheimer's disease (BLAZE). Alzheimers Res Ther. 2018;10:96.

10. Asnaghi V, Lin H, Rabbia M, Ostrowitzki S, Smith J, Cho W. Long-term safety and tolerability of escalating doses of crenezumab in patients with mild-tomoderate Alzheimer's disease. Neurology. 2017;88(Suppl 16):6.083.

11. Asnaghi V, Lin H, Hu N, Smith J, Cho W, Ostrowitzki S. Safety and tolerability of crenezumab in mild-to-moderate AD patients treated with escalating doses for up to 25 months. Alzheimers Dement. 2017;13:P602.

12. Kerchner GA, Asnaghi V, Rabbia M, Ward M, Quartino A, Honigberg L, et al. A phase $\mathrm{Ib}$, randomized, double-blind, placebo-controlled, multiple dose study to assess the safety, tolerability and pharmacokinetics of escalating doses of crenezumab in patients with mild-to-moderate AD. J Prev Alz Dis. 2016;3(Suppl 1):OC5

13. ClinicalTrials.gov. CREAD study: a study of crenezumab versus placebo to evaluate the efficacy and safety in participants with prodromal to mild Alzheimer's disease (AD). ClinicalTrials.gov Identifier: NCT02670083. https:// clinicaltrials.gov/ct2/show/NCT02670083. Accessed 8 July 2019.

14. ClinicalTrials.gov. A study of crenezumab versus placebo to evaluate the efficacy and safety in participants with prodromal to mild Alzheimer's disease (AD) (CREAD 2). ClinicalTrials.gov Identifier: NCT03114657. https:// clinicaltrials.gov/ct2/show/NCT03114657. Accessed 8 July 2019.

15. F. Hoffmann-La Roche Ltd. Roche to discontinue phase III CREAD 1 and 2 clinical studies of crenezumab in early Alzheimer's disease (AD) other company programmes in $A D$ continue [media release]. 30 January 2019. https://www.roche.com/media/releases/med-cor-2019-01-30.htm. Accessed 8 July 2019

16. ClinicalTrials.gov. A study of crenezumab versus placebo in preclinical presenilin1 (PSEN1) E280A mutation carriers to evaluate efficacy and safety in the treatment of autosomal-dominant Alzheimer's disease (AD), including a placebo-treated non-carrier cohort. https://clinicaltrials.gov/ct2/show/ NCT01998841. Accessed 6 Aug 2019.

17. Yang T, Dang Y, Ostaszewski B, Mengel D, Steffen V, Rabe C, et al. Target engagement in an Alzheimer trial: crenezumab lowers amyloid $\beta$ oligomers in cerebrospinal fluid. Ann Neurol. 2019;86:215-24.

18. Toledo JB, Vanderstichele H, Figurski M, Aisen PS, Petersen RC, Weiner MW, et al. Factors affecting $A \beta$ plasma levels and their utility as biomarkers in ADNI. Acta Neuropathol. 2011;122:401-13.

19. Bittner T, Zetterberg H, Teunissen CE, Ostlund RE Jr, Militello M, Andreasson $U$, et al. Technical performance of a novel, fully automated electrochemiluminescence immunoassay for the quantitation of $\beta$-amyloid (1-42) in human cerebrospinal fluid. Alzheimers Dement. 2016;12:517-26.
20. Dua P, Hawkins E, van der Graaf PH. A tutorial on target-mediated drug disposition (TMDD) models. CPT Pharmacometrics Syst Pharmacol. 2015: 4:324-37.

21. Lindbom L, Pihlgren P, Jonsson EN. PsN-Toolkit--a collection of computer intensive statistical methods for non-linear mixed effect modeling using NONMEM. Comput Methods Prog Biomed. 2005;79:241-57.

22. Deng R, lyer S, Theil FP, Mortensen DL, Fielder PJ, Prabhu S. Projecting human pharmacokinetics of therapeutic antibodies from nonclinical data: what have we learned? MAbs. 2011;3:61-6.

\section{Publisher's Note}

Springer Nature remains neutral with regard to jurisdictional claims in published maps and institutional affiliations.
Ready to submit your research? Choose BMC and benefit from:

- fast, convenient online submission

- thorough peer review by experienced researchers in your field

- rapid publication on acceptance

- support for research data, including large and complex data types

- gold Open Access which fosters wider collaboration and increased citations

- maximum visibility for your research: over $100 \mathrm{M}$ website views per year

At BMC, research is always in progress.

Learn more biomedcentral.com/submissions 